\title{
The Use of Deep Radial Consolidation method - CPR: Monitoring the Evolution of Densification of the Compressible Layer, the Construction of a Port in Itacoatiara City-AM
}

\author{
Raphaela Ribeiro Valero ${ }^{1}$, Evailton Arantes de Oliveira ${ }^{2}$, Marco Antônio Guerreiro Prado Filho ${ }^{3}$, Charles \\ Ribeiro de Brito ${ }^{2}$
}

1,2,4 UNINORTE-Laureate Internacional Universities. Rua Joaquim Nabuco, No 1615. Manaus/AM - Brasil. CEP: 69020-030

${ }^{3}$ UFPA- Universidade Federal do Pará-Pará-Brazil.

E-mail: raphaelavalero@gmail.co, arantestop@hotmail.com, marcoguerreiroprado@hotmail.co, charles.brito@uninorte.com.br

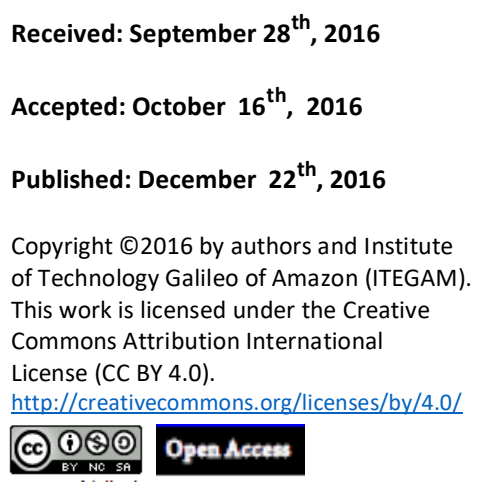

Received: September $28^{\text {th }}, 2016$

Accepted: October $16^{\text {th }}, 2016$

Copyright $(2016$ by authors and Institute of Technology Galileo of Amazon (ITEGAM) work is licensed under the Creative ns Attribution International cc) (i) (2) (2) Open Acees:

\begin{abstract}
This document describes the implementation of the foundation of technique, deep radial CPRconsolidation used in the construction of the new port in Itacoatiara city -AM. The method adopted is intended to treat the soil. This treatment is performed when the geomechanical characteristics are applied for carrying structures. Since the region is composed of original soil sandy sediment formations, sandy-silty and sandy clay of low cohesion, a phenomenon known as " Fallen Lands " Because of these factors, the soil presents little resistance to the action of causative agents of the phenomenon, such as the hydrodynamic pressure, hydrostatic pressure, structural and neotectonic factors, climatic factors, lithologic, and anthropogenic. The use of CPR aims to soil pore pressure dissipation making it stable. In order to reduce and neutralize the forces acting and increase the resistant forces. Specific objectives will be discussed the method in their steps detailing the geotechnical properties and procedures of instrumentation, showing that the applied technique is the solution for soil treatment in certain places applied to it, according to the polls.
\end{abstract}

Keywords: Method CPR-Consolidation Deep Radial, Improving the region, Drains mesh DVFs.

\section{O Uso do Método de Consolidação Profunda Radial - CPR:} Acompanhamento da Evolução dos Adensamentos da Camada Compressível, na Construção de um Porto na Cidade de Itacoatiara-AM

\begin{abstract}
RESUMO
Este documento descreve a execução da técnica de fundação, CPR-consolidação profunda radial utilizada na construção do novo Porto no município de Itacoatiara-AM. O método adotado tem por objetivo fazer o tratamento do solo. Este tratamento é executado quando as características geomecânicas não são aplicadas para a execução de estruturas. Uma vez que, a região é composta por solos de origem de formações de sedimentos arenosos, areno-siltosos e areno-argilosos de baixa coesão, fenômeno conhecido como "Terras Caídas" Devido estes fatores, o solo apresenta pouca resistência à ação dos agentes causadores do fenômeno, como: a pressão hidrodinâmica, pressão hidrostática, fatores estruturais e neotectônicos, fatores climáticos, litológico, e antropogênico. $\mathrm{O}$ emprego do CPR visa à dissipação de poropressão do solo tornando-o estável. Objetivando reduzir e neutralizar as forças atuantes e aumentar as forças resistentes. Como objetivos específicos serão abordados o método em suas etapas detalhando as propriedades geotécnicas e procedimentos da instrumentação, mostrando que a técnica aplicada é a solução para o tratamento do solo em determinados locais nele aplicado, de acordo com as sondagens.
\end{abstract}

Palavras Chaves: Método CPR- Consolidação Profunda Radial Melhorias regionais, Malha de drenos DVFs. 


\section{INTRODUÇÃO}

As condições geológicas e geotécnicas da região portuária são completamente afetadas pelos sucessivos aterros executados que são técnicas de reforço de solo na região ribeirinha. O desafio geotécnico para estas regiões é evitar presentes rupturas nos aterros, e principalmente pelo cíclico fenômeno do rápido esvaziamento das águas dos rios.

A execução do CPR foi justificada pelo tipo do solo apresentar formações de vários sedimentos e recalques elevados, que por consequência trazem baixa resistência ao solo em relação às tensões admissíveis aplicadas.

A aplicação do método é específica para o tratamento de solos moles, segundo a NBR 6484 [1], a terminologia muito mole é para solos com SPT menor que 2 golpes $/ 30 \mathrm{~cm}$, ou existem ainda solos extremamente moles com SPT igual a 1 e resistência não drenada menor que $12 \mathrm{kPa}$.

O resultado da aplicação de CPR é a formação de um material compósito constituído por rigidez (colunas de compressão) e adensamento, comprimido e confinado (solo tratado).

Acrescentaram que o novo material compósito tem suas propriedades de rigidez e resistência melhoradas. Como consequência desta melhoria, há a redução da magnitude dos recalques e o aumento no fator de segurança em termos de estabilidade de aterro.

As melhorias do solo são de acordo pelas características geotécnicas do material de fundação, que inicialmente não são adequadas para a execução de estruturas que solicitarão o solo além da sua capacidade de suporte.

Posteriormente, com o solo tratado evitará problemas como: recalques pós-construtivos maiores do que os admissíveis (estado limite de utilização) ou, em caso extremo, rupturas (estado limite último).

\section{REVISÃO BIBLIOGRÁFICA}

\section{II.2 MELHORIAS DO SOLO DE FUNDAÇÃO NA REGIÃO PORTUÁRIA}

A melhoria de solos tem como objetivo: aumentar a resistência ao cisalhamento, aumentar a capacidade de carga, aumentar a densidade, transferir as cargas do aterro para as camadas mais competentes, controlar as deformações, acelerar o adensamento, reduzir as cargas impostas a fundação, proporcionar estabilidade, preencher vazios e aumentar a resistência a liquefação.

Em termos técnicos, o conceito de melhoria do solo é a modificação da área do solo de fundação ou projeto de estrutura a fim de proporcionar um melhor desempenho sob condições de projeto ou carregamento operacional, como prevê a USACE a Federal Highway Administration (FHWA), agência do departamento de transporte rodoviário dos Estados Unidos, a melhoria do solo pode ser efetuada pela modificação das suas características originais com ou sem o acréscimo de outro tipo de material.

\section{II.3 CONDIÇÕES DO SOLO NA ÁREA PORTUÁRIA}

As análises iniciais feitas por sondagens, objetiva o estudo do solo mostrando as características de variações dos tipos de solos presentes. A figura 1 demostra características típicas do tipo de solo apresentado na região de Itacoatiara portuária analisada. Os solos são de camadas de argila arenosa/siltosa e areia fina/média até $25 \mathrm{~m}$ de profundidade.

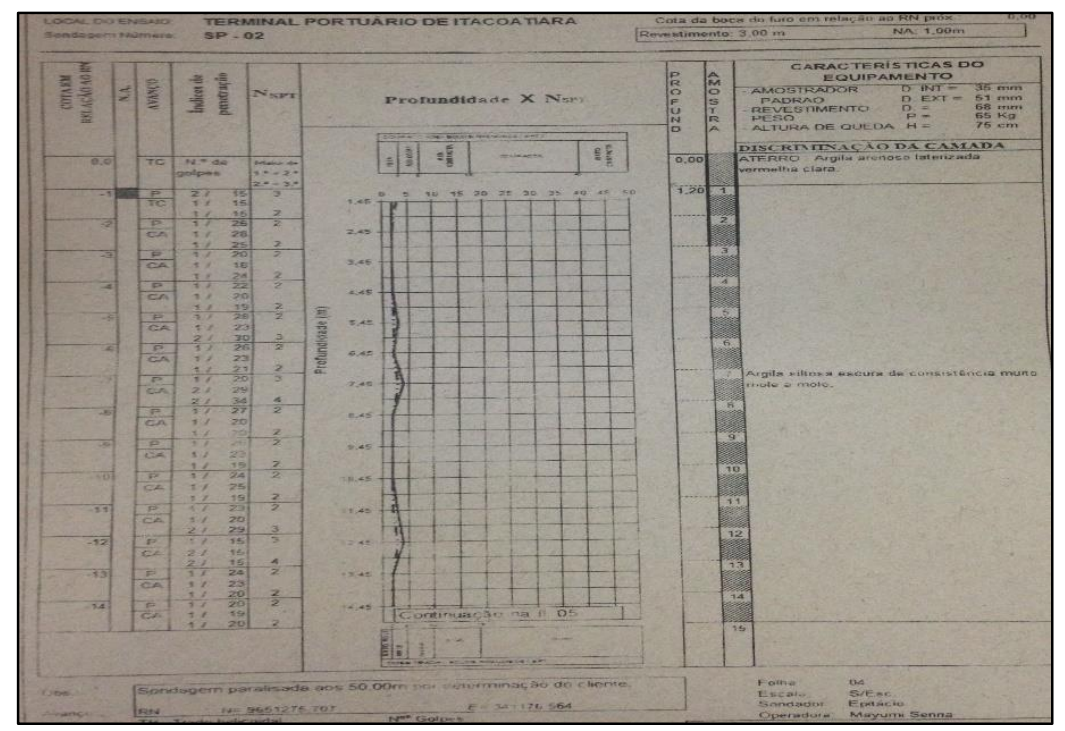

Figura 1. Laudo de sondagem.

Fonte: Empresa JN NASSER, (2015).

De forma característica toda a extensão da área portuária, há predominância de várias camadas de aterro, com formações de 
sedimentos, apresentando compostos de areias finas ou média pouco compactada.

A resistência ao cisalhamento não drenada ao longo de $25 \mathrm{~m}$ de profundidade, obtida com sondagens pressiométricas de certificação do CPR, antes do tratamento, variava de $2 \mathrm{kPa}$ a 20 $\mathrm{kPa}$. Devido ao nível do rio apresentar variação de vazantes entre os meses de Junho a Novembro, e de forma características as rupturas ocorreram nos meses se Agosto e Setembro, caracterizase predominância do fenômeno das terras caídas.

\section{II.4 CPR- CONSOLIDAÇÃO PROFUNDA RADIAL - BASE TEÓRICA DO MECANISMO DO COMPACTION GROUTING.}

O histórico de rupturas e deformações associado ao risco permanente de instabilidade presentes na região exige serviços de reforço de solo, preferencialmente, com base em seu adensamento de forma ativa. A solução para este tipo de problema foi a CPRConsolidação Profunda Radial.

A adoção de novas técnicas como a do CPR partiu-se de necessidades diante a problemáticas surgidas como exemplo a da técnica mundialmente conhecida como compaction grouting, um método de melhoramento de solos aplicado a mais de 50 anos.

$\mathrm{O}$ compaction grouting tem início com a perfuração do solo. O processo de injeção da argamassa ocorre em estágios, e é executada de baixo para cima segundo taxas de injeção controladas, a argamassa geralmente toma um formato esférico, a técnica não deve ser aplicada no tratamento de espessas camadas de solo saturado siltoso ou argiloso. A argamassa de cimento é injetada sobre elevada pressão no interior da massa de solo. Este processo tende a promover o deslocamento e a aproximação das partículas ao redor da argamassa expandida, e consequentemente uma redução nos volumes de vazios entre partículas, prelinarmente ocupados por água ou ar.

Assim, a diferença entre o método CPR e o compaction grouting é a utilização do dreno pré-fabricado, introduzindo este elemento ao processo. $\mathrm{O}$ seu emprego visa acelerar a dissipação de poropressão, buscando desta forma tornar a técnica mais eficiente.

\section{II.5 PRINCIPAIS MÉTODOS DE TRATAMENTO DE SOLOS}

Remanejamento de solos: Consiste em extrair o solo de baixa resistência, substituindo-o por um solo estudado e adensado, para atender aos esforços a que vai ser solicitado. Atualmente esta metodologia está sofrendo um grande acréscimo de custo, pois os órgãos de defesa ambiental estão exigindo o tratamento do solo orgânico.

Jet Grouting: Consiste introduzir no solo uma haste, tendo na sua extremidade uma hélice, pelo qual é injetado no solo um grouting com altíssima pressão (50 a 70MPa) e alto slump. Com isso, são formadas colunas de grouting no solo, com certas profundidades até atingir o solo resistente. Conforme as estacas este sistema fará transferência direta das cargas da estrutura para o solo resistente.

Vibrocompactação: Estabiliza os solos moles através da criação de colunas formadas por material granular, produzidas pela penetração de estacas vibrantes, e pesadas no interior do maciço. É usada para tratamento profundo de solos de baixa capacidade de suporte, permitindo o aumento de sua densidade e resistência, além de redução de sua compressibilidade, uma vez que altera a permeabilidade.

\section{MATERIAIS E MÉTODOS}

O método conhecido como consolidação profunda radial (CPR) apresenta-se como uma nova técnica de tratamento de solos moles. Desenvolvida pela empresa Engegraut, datado em: 21/08/2009 [2].

Esta tecnologia consiste no bombeamento, a alta pressão, de uma mistura de solo denominada de grout, que permite a compactação e o aumento da densidade do solo mole, circundado por geodrenos especiais previamente instalados.

\section{III.2 METODOLOGIA DE EXECUÇÃO EM CAMPO}

Antes de iniciar o método do CPR é necessário executar alguns serviços preliminares a fim de garantir qualidade nas etapas posteriores. É realizada a limpeza da área, com a remoção de possíveis interferências, e a execução de uma camada de aterro de sacrifício, sem irregularidades, para permitir o acesso dos equipamentos ao longo do trecho a ser tratado.

\section{III.3 ANÁLISE DE SOLOS LOCAIS}

Inicialmente é realizado uma investigação geotécnica visando identificar e analisar as características dos solos locais. Esta etapa é fundamental para o reconhecimento da camada a ser tratada e a definição das principais diretrizes do processo de tratamento, tal como o espaçamento, diâmentro e profundidades das colunas. Est análises são verificadas através do ensaio a SPT, que conforme a figura 2 demonstra os materiais necessários para recolhimento das amostras em campo, para posteriormente ser analisado em relação ao valor Nspt.

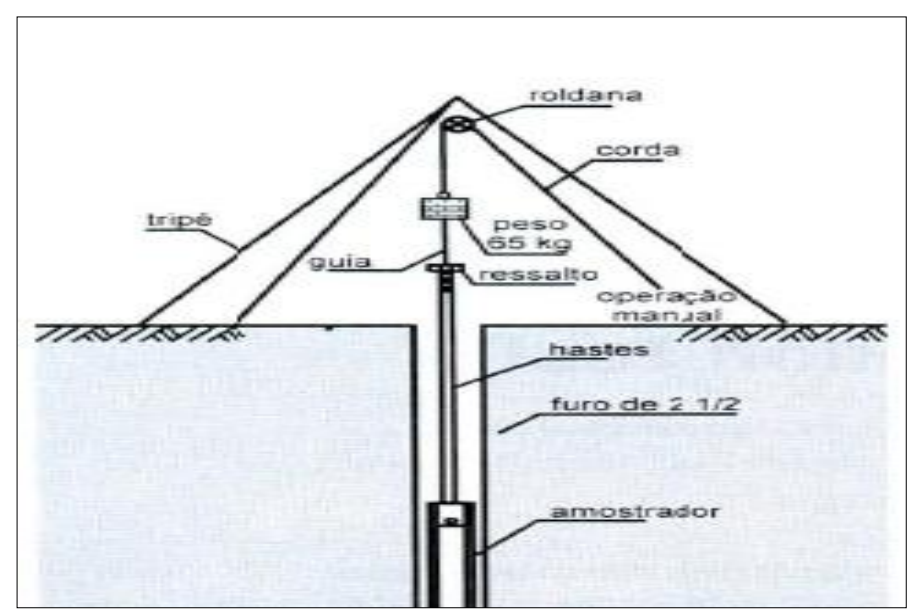

Figura 2. Ilustração Ensaio SPT.

Fonte: Autores, (2015).

\section{III.4 MARCAÇÃO E INSTALAÇÃO DE GEODRENOS}

Inicialmente são feitos pré-furos através do estudo das camadas de solo. A lança do suporte mandril, acoplada a 
escavadeira hidráulica sobre esteiras deve ter compatibilidade a profundidade marcada, conforme a figura 3. A análise dos drenos pré-fabricados é realizada através da obtenção de um diâmetro equivalente entre este elemento e um dreno de areia. Para o autor demonstrou que o diâmetro equivalente ao dreno da areia (dw) pode-se ser obtido admitindo-se um círculo de perímetro equivalente a um retângulo do dreno vertical geossintético. Com isso foi utilizado geodrenos pré-fabricados verticais e executada a malhas espalhadas por toda a área de tratamento, conforme a figura 4.

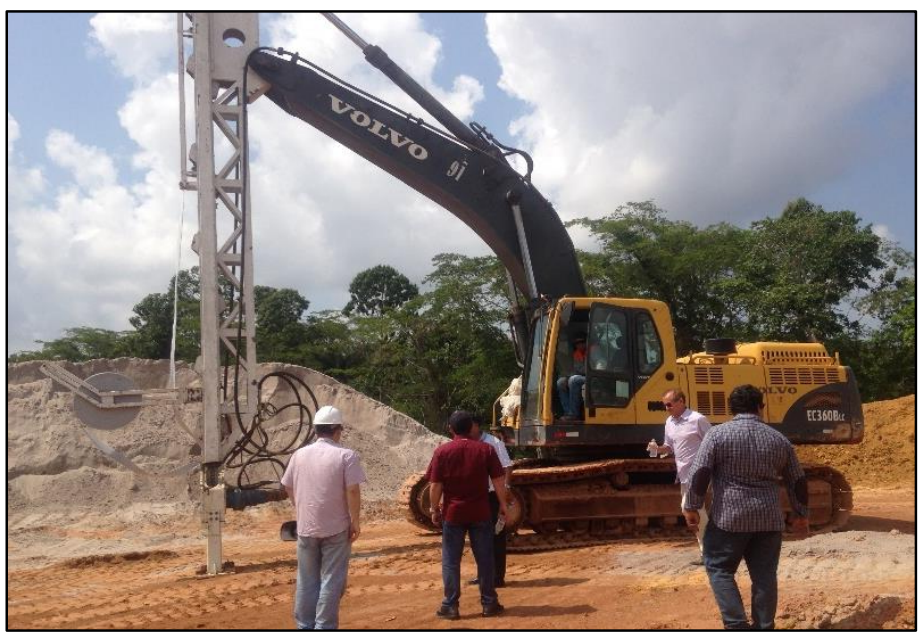

Figura 3. Escavadeira hidráulica sobre esteiras.

Fonte: Autores, (2015).

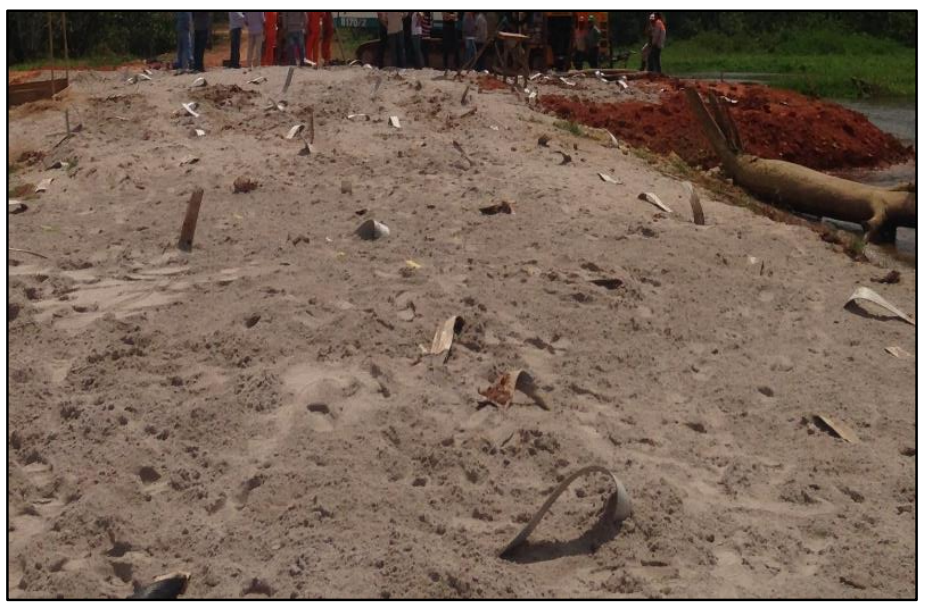

Figura 4. Geodrenos pré-fabricados.

Fonte: Autores, (2015).

\section{III.5 MARCAÇÃO PARA INJEÇÃO DO GROUT}

Após instalação dos geodrenos, inicia a marcação com os piquetes paralelamente ao material drenante, são posicionados e instalados os tubos de bombeamento, responsáveis por guiar o grout até o ponto de geração dos bulbos, conforme a figura 4 .

\section{III.6 BOMBEAMENTO DO COMPOSTO}

O grout utilizado foi definido através de um composto formado por argila $30 \%$, areia $65 \%$, e $5 \%$ de aditivos do tipo cimento e aglutinantes. Esta mistura é bombeada e posteriormente injetada no solo. É realizada a mistura através de um multimisturador com bicos injetores dispostos em pás rotativas, que são acopladas ao braço hidráulico de uma escavadeira tipo CAT 330 que realiza movimentos de translação e rotação em diversas direções e profundidades, misturantes os aglomerantes até a formação do composto, conforme a figura 5. A formação de cada bulbo é realizada em etapas e controlada em campo através de curvas de pressão por volume. A pressão adotada é no mínimo $\left(10 \mathrm{~kg} / \mathrm{cm}^{2}\right)$. Neste caso a pressão para formação dos bulbos foi de mais ou menos $9 \mathrm{kgf} / \mathrm{cm} 2$ ou $(900 \mathrm{kPa})$, verificado por um auxílio de manômetro, conforme a figura 6.

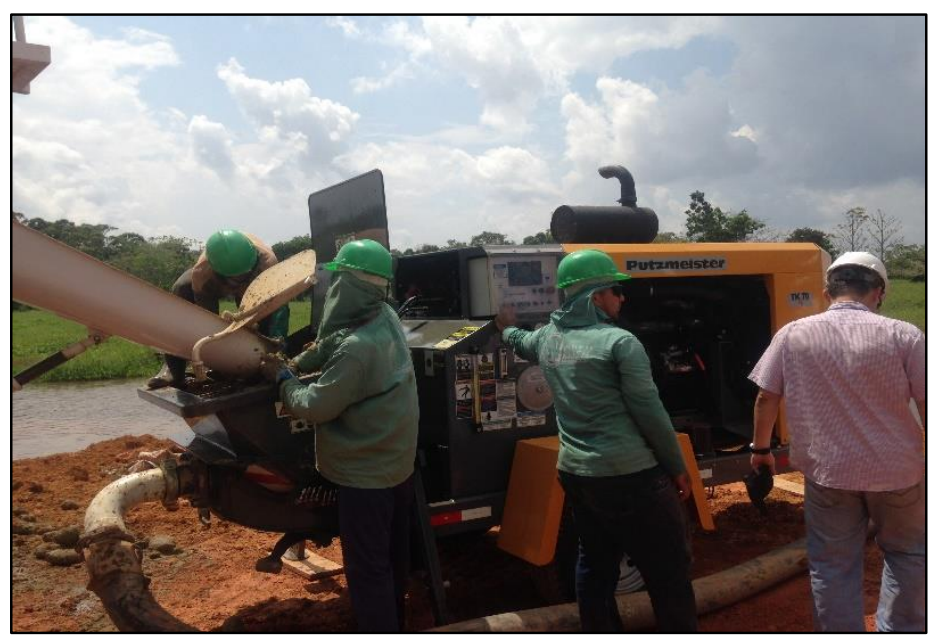

Figura 5. Bombeamento do composto grout.

Fonte: Autores, (2015)

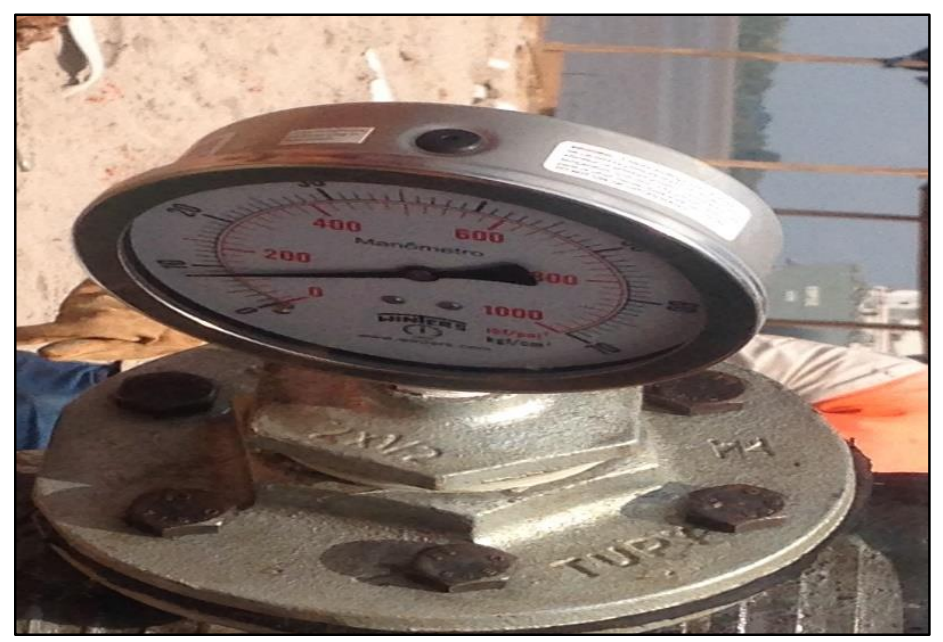

Figura 6. Manômetro.

Fonte: Autores, (2015).

\section{III.7 FORMAÇÃO DOS BULBOS}

As elevadas pressões exercidas durante o processo de injeção da argamassa resultam um sistema complexo de elevadas tensões radial e tangencial, as quais acarretam grandes deslocamentos do solo no entorno do bulbo em formação. Em 
consequência, a água é forçada a fluir da matriz de solo mole, por drenagem radial, através da malha de geodrenos instalados.

A solução propõe a formação de bulbos no interior da camada do solo mole, que transferem as cargas do bombeamento para o solo local, fazendo uma compressão lateral nesta camada e o consequente aumento da pressão neutra. Assim, estando a água em carga superior à que estabelecida equilíbrio com o meio externo, surge um gradiente que promove a percolação da água em direção a malha de geodrenos instaladas na região e daí para a camada de solo mole.

\section{III.8 PROGRAMA DE INSTRUMENTAÇÃO}

Após a verificação da execução do CPR, é realizado uma bateria de ensaios de prova a confirmar a validação das camadas. Com o objetivo de acompanhar a evolução dos adensamentos da camada compressível. Foram instalados piezômetros. Os piezômetros têm a função de mostrar a grandeza das sobre pressões neutras atuantes nas camadas de solos moles, a partir das quais serão controladas a evolução desde o início ao término do recalque, quando as pressões se dissiparem, serve para medir as pressões estáticas e a compressibilidade dos líquidos presentes nos locais de execução do método de tratamento.

\section{RESULTADOS E DISCUSSÕES}

A área de estudo corresponde ao município de Itacoatiara localiza-se a margem esquerda do rio Amazonas, a leste do Estado, ligado pela rodovia AM-010 a 266km. Distante $175 \mathrm{~km}$ em linha reta e $201 \mathrm{~km}$ via fluviais. Suas coordenadas cartesianas situamse: $3^{\circ} 8^{\prime} 54^{\prime \prime}$ de latitude Sul e a $58^{\circ} 25^{\prime}$ de longitude a Oeste de Greenwich. O terminal portuário é composto por uma rampa de concreto para atracação de balsas, duas pontes de acesso móveis, e por dois flutuantes, um intermediário e outro principal. $\mathrm{O}$ flutuante principal tem dimensões: $75 \mathrm{~m}$ de comprimento, $22 \mathrm{~m}$ de boca e $2,4 \mathrm{~m}$ de pontal e um flutuante intermediário de $21 \times 8 \times 2 \mathrm{~m}$. O sistema de acesso é formado por duas pontes móveis de $45 \mathrm{~m}$ cada, conforme mostra as figuras 7 e 8 .

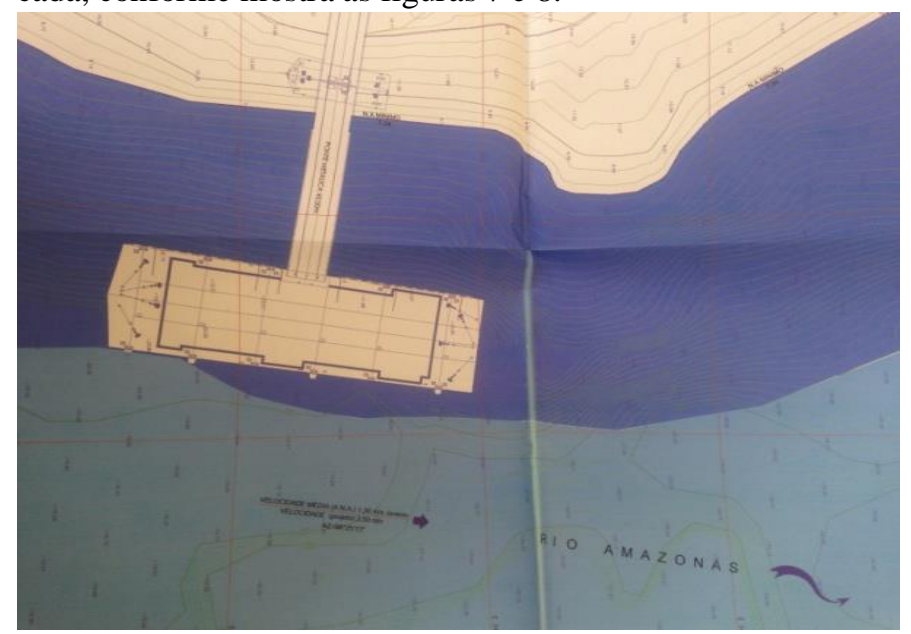

Figura 7. Implantação da IP4 .

Fonte: Autores, (2015).

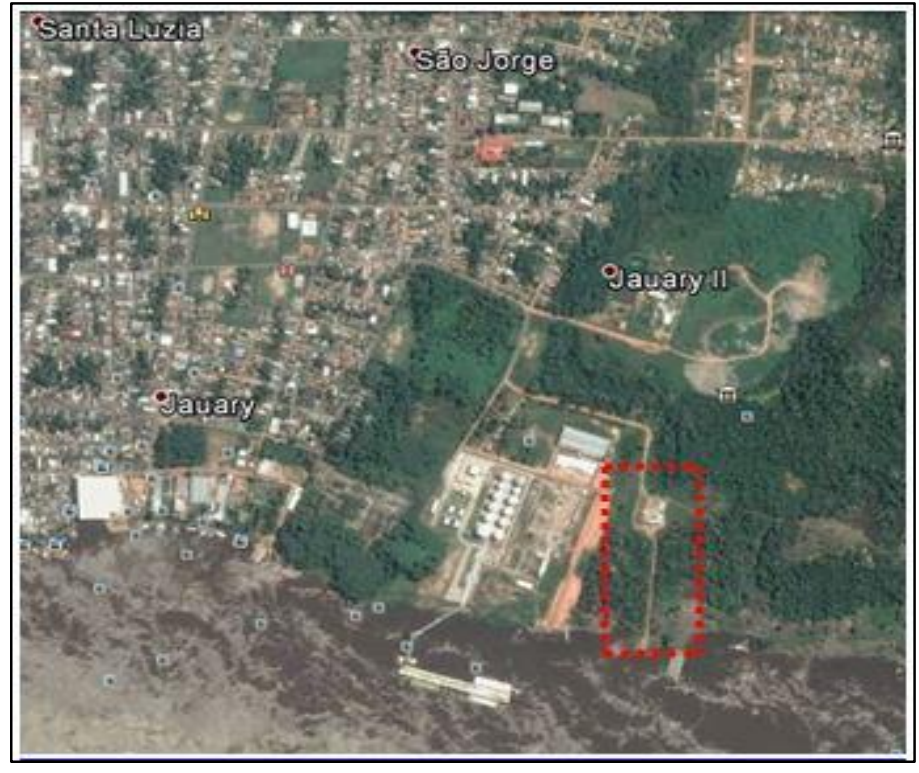

Figura 8. Posição Geográfica IP4.

Fonte: [3].

\section{IV.2 IMPORTÂNCIA DO PORTO PARA A REGIÃO}

A construção do Porto no município de Itacoatiara no estado do Amazonas terá avanços econômicos, uma que a região depende deste tipo de escoamento por ser uma característica da região. Esta construção visa ligar transportes no município em direção ao exterior, com reduções de tempo e custo operacional. A redução no tempo de transporte será entre 10 e 15 dias. O antigo canal tinha capacidade para escoamento de 360 milhões de toneladas em cargas. A nova ampliação permite a passagem de 600 milhões de toneladas (Ferreira, G.).

Com esses avanços de melhorias no canal, favorece o escoamento de grãos que saem da região Norte em direção à Ásia e à Europa. Por um lado, depende-se da construção de rotas que passam pelo Arco Norte e pelo Canal do Panamá. Mas, por outro lado, haverá uma economia no tempo de viagem que deve sair de 40 para 25 ou 30 dias de deslocamento, com menor custo.

Esta é uma oportunidade para tornar o Brasil mais competitivo, priorizando principalmente o Arco Norte que vem de encontro aos novos portos que estão sendo construídos. O canal vem somar, e complementar à atividade de rotas de transporte fluvial.

\section{IV.3 ESTUDO DE CASO}

O fenômeno Terras Caídas é um acontecimento natural que se manifesta através do desbarrancamento ou desprendimento das margens dos rios com deslocamento de solo para dentro do leito. Este fenômeno é oriundo das características de formações e parâmetros que atuam como fatores limitantes do solo da região do Amazonas.

Nesse sentido, terras caídas são eventos configurados por processos diversos nos quais ocorrem deslocamentos de solos, sedimentos ou rochas de vários tipos. Considerando a perspectiva regional, encontram-se fluxos de sedimentos, abatimentos, 
deslizamentos, desmoronamentos e desabamentos, constituindose, portanto de diferentes mecanismos de movimentação de massa, e diversos materiais deslocados em diferentes velocidades dependendo do processo ocorrido.

Esse fenômeno associa-se inicialmente as ações erosivas promovidas pelo próprio rio, relacionadas a vários fatores de origens diferentes que se interligam em algum momento. Dessa forma, observa-se que as Terras Caídas são eventos que modificam a morfologia das margens do rio, ou seja, participam da reestruturação da paisagem local.

Os boletins das sondagens realizadas em vários pontos locais indicaram a presença de solos aluvionares constituídos por: argilas com matéria orgânica, pedaços de madeira troncos, folhas e restos de vegetais em decomposição de cor preta ou marrom, conforme a figura 9. Esta camada encontra-se sobreposta aos solos residuais do tipo silte arenoso, pouco argiloso, variegado, fofo a muito compactado. Isso esta presente pela análise da existência de um aterro, construído sobre a camada aluvionar, provavelmente executado para possibilitar a ocupação territorial que existia nessas áreas antes das desapropriações realizadas para a construção do Porto de Itacoatiara.

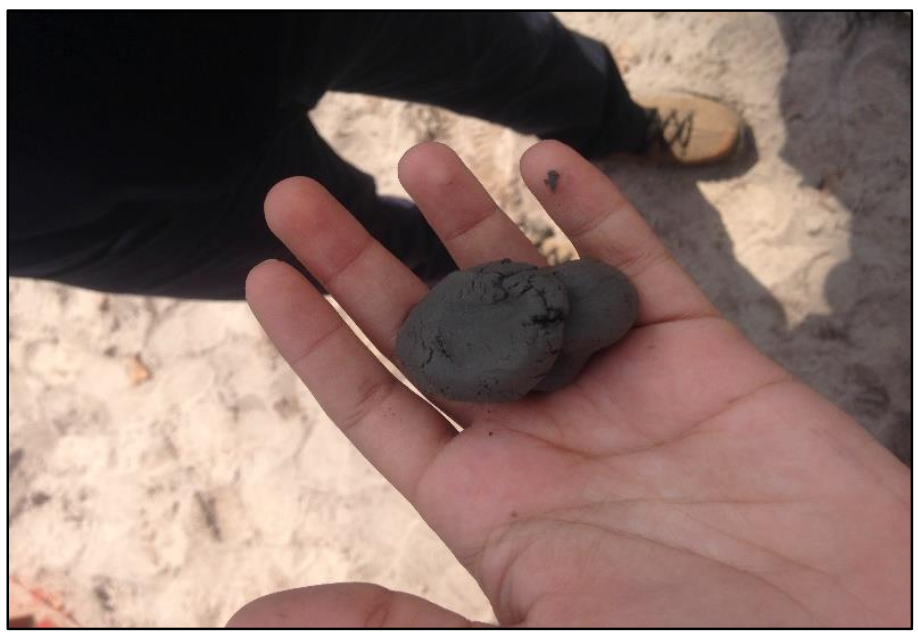

Figura 9. Tipo de solo da região.

Fonte: Autores, (2015).

\section{IV.3.1TÉCNICA APLICADA/CONSOLIDAÇÃO PROFUNDA RADIAL}

A técnica aplicada na construção foi a: "CPR" Consolidação Profunda Radial. Tem por suas etapas construtivas: a instalação de geodrenos, preparação de argamassa e bombeamento, ensaios de SPT para verificação inicial e final dos resultados no solo. No anexo 2 é demonstrado o esquema de aplicação do método citado.

Inicialmente, são feitos pré-furos, a fim de permitir ou facilitar a instalação de geodrenos.

O dreno vertical pré-fabricado reduz os comprimentos de drenagem e tirar vantagem da permeabilidade dos solos na direção horizontal (radial), geralmente mais elevada, acarretando, com isto, a redução de tempo para que o processo de adensamento ocorra, conforme a figura 10.

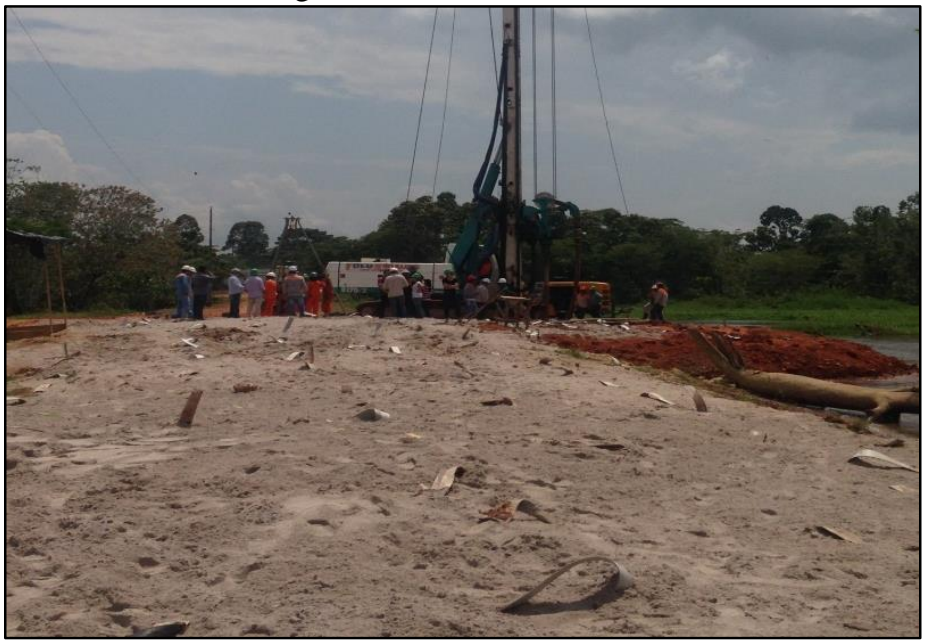

Figura 10: Instalação de Geodrenos.

Fonte: Autores, (2015).

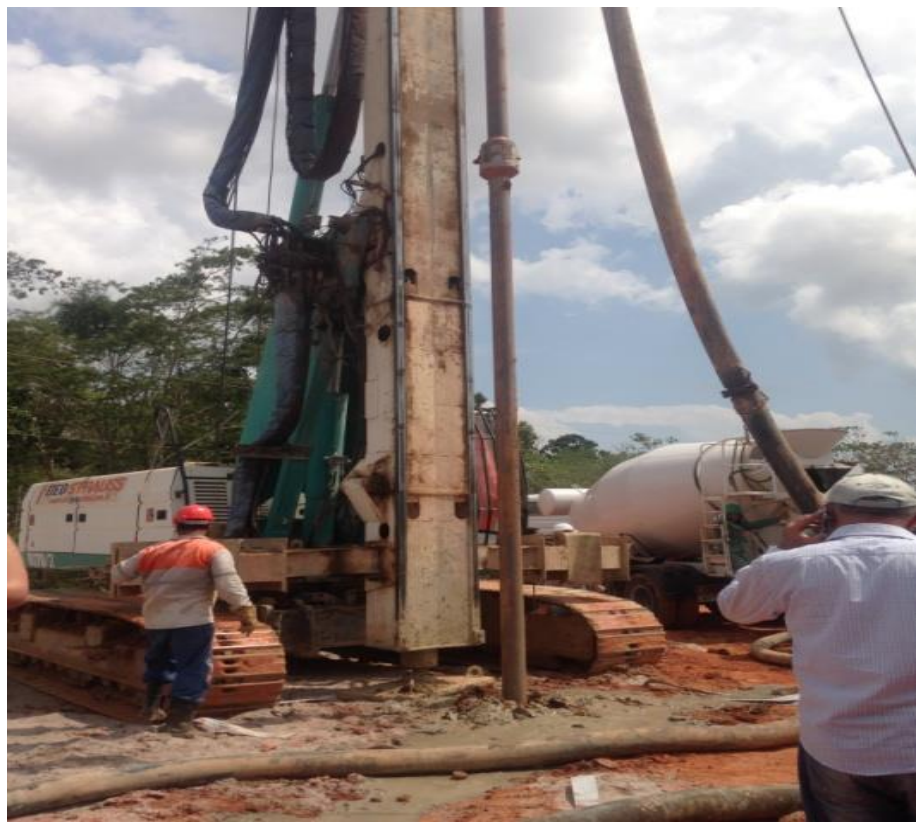

Figura 11: Injeção da argamassa.

Fonte: Autores, (2015).

Este processo tende a promover o deslocamento e a aproximação das partículas do solo ao redor da argamassa expandida e, consequentemente, uma redução nos volumes de vazios entre partículas, preliminarmente ocupados por ar e/ou água, demonstrado nas Figura 12 e 13. 


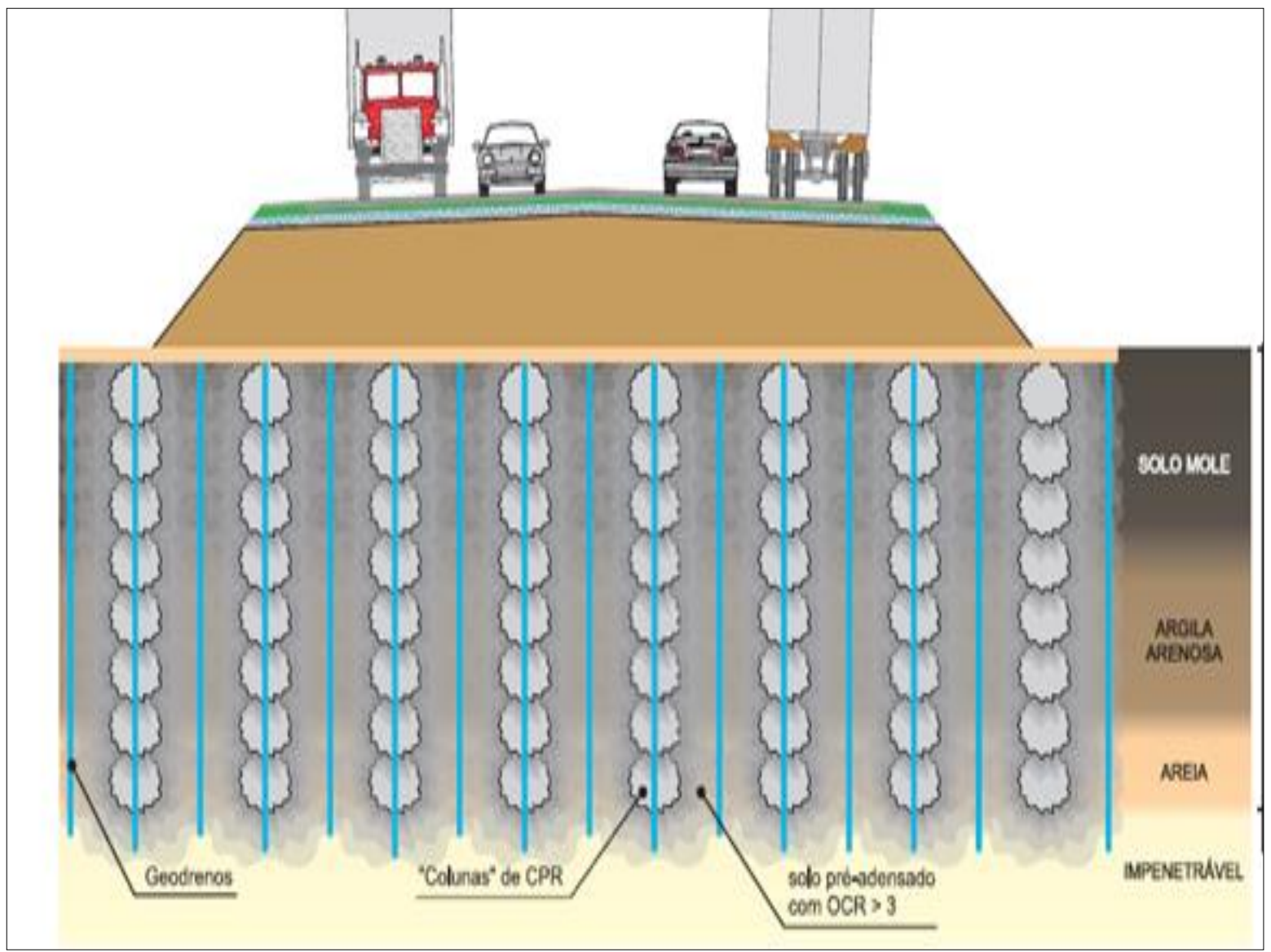

Figura 12: Método CPR - Consolidação Profunda Radial.

Fonte: [8].

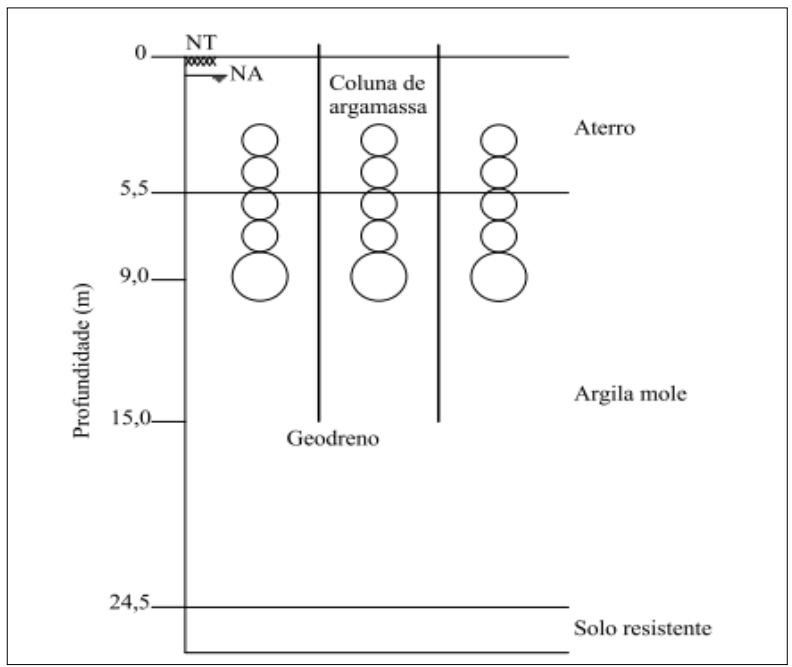

Figura 13: Esquema de aplicação do CPR.

Fonte:[4].

A formação dos bulbos de compressão ocorre segundo um alinhamento vertical, de baixo para cima, na massa de solo mole. As pressões da injeção variam de 100 a $1000 \mathrm{kPa}$, reduzindo a medida que se aproxima da superfície do terreno..
As elevadas pressões exercidas durante o processo de injeção da argamassa resultam em um sistema complexo de elevadas tensões radiais e tangenciais, as quais acarretam grandes deslocamentos do solo no entorno do bulbo de formação. Em consequência, a água é forçada a fluir da matriz do solo mole, por drenagem radial, através da malha de geodrenos instalados . 
Em argilas saturadas, onde a aplicação da argamassa solo cimento não é efetiva, a expansão da argamassa induz o aumento de poro-pressão na massa de solo, o que limita a eficiência da técnica a fim de melhorar o solo. Assim, a técnica incorporou a experiência mundial acumulada no meio técnico com o uso de dreno vertical pré-fabricado, introduzindo este elemento ao processo. O seu emprego visa a acelerar a dissipação de poropressão, buscando, desta forma, tornar a técnica mais eficiente.

Para verificações do solo e acompanhamento do aumento de sua resistências, em avaliações de desempenho da técnica de CPR têm-se realizado através de monitoramentos de propressão com piezômetro elétrico de corda vibrante, a análise de resistência e rigidez por meio de ensaios pressiométricos e o acompanhamento de deslocamentos verticais com placas de recalques.

A análise de resistência inicial foi feito através da sondagem, Standart Penetration Test (SPT), que permite a determinação do perfil geológico e a capacidade de carga das diferentes camadas do subsolo, a coleta de amostras destas camadas, a verificação do nível do lençol freático, a determinação da compacidade ou consistência dos solos arenosos ou argilosos, respectivamente e também a determinação de eventuais linhas de ruptura que possam ocorrer em subsuperfície. Em cada ponto de sondagem, monta-se uma torre (tripé), com altura em torno de 5 metros e um conjunto de roldanas e cordas, que auxiliará no manuseio da composição de hastes por força manual.

A amostra a zero metro é coletada e inicia-se a escavação com trado manual; na base do furo apoia-se o amostrador padrão acoplado a hastes de perfuração; marca-se na haste, com giz, um segmento de $45 \mathrm{~cm}$ dividido em trechos iguais de $15 \mathrm{~cm}$; ergue-se o martelo padronizado ou "peso batente" de $65 \mathrm{~kg}$ até a altura de $75 \mathrm{~cm}$ e deixa-se cair em queda livre sobre a haste. Tal procedimento é repetido até que o amostrador penetre $45 \mathrm{~cm}$ do solo; a soma do número de golpes necessários para a penetração do amostrador nos últimos $30 \mathrm{~cm}$ é o que dará o índice de resistência do solo na profundidade ensaiada (NSPT), conforme a figura 14 .

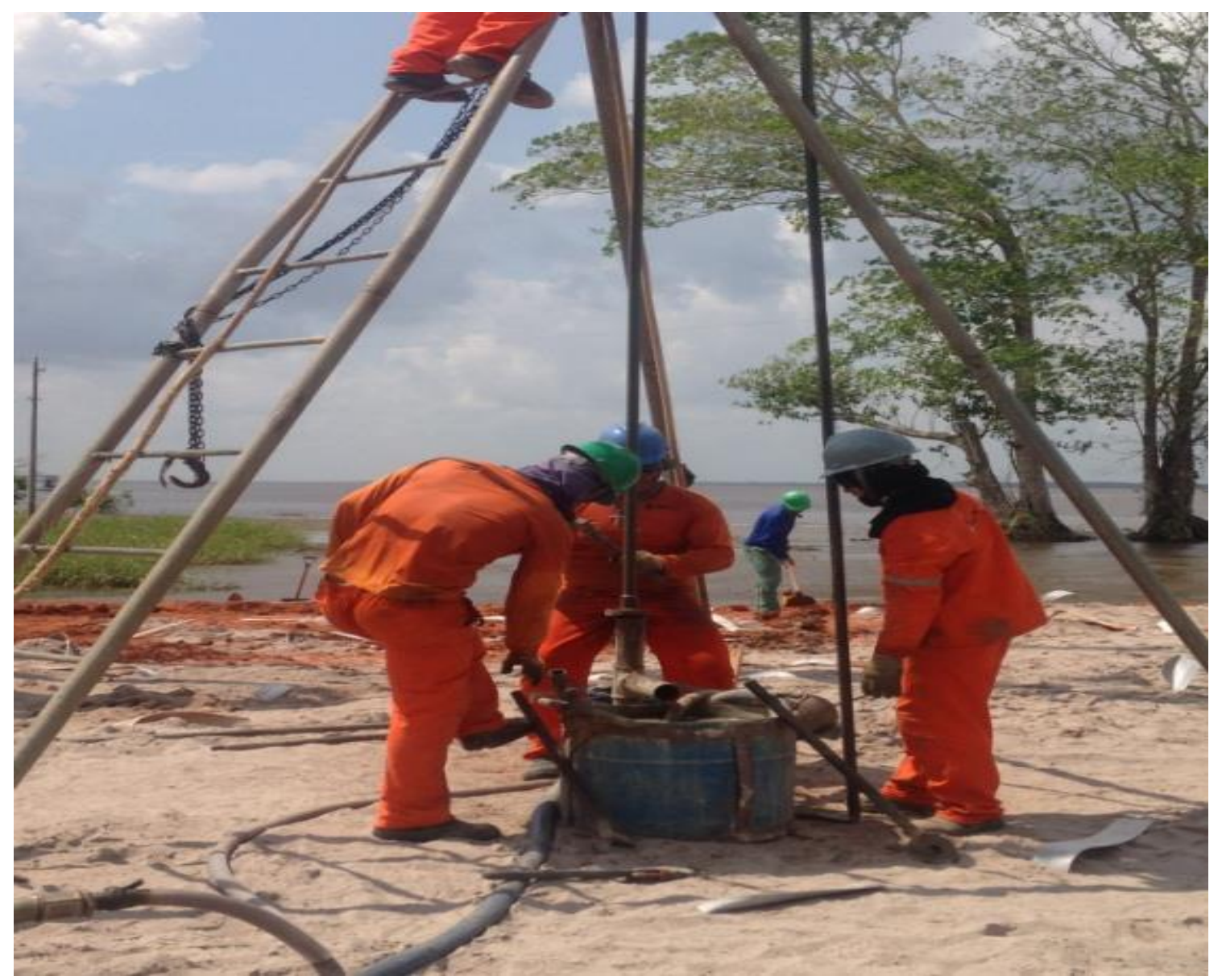

Figura 14: Sondagem SPT.

Fonte: Autores, (2015).

\section{IV.4 CERTIFICAÇÃO DO MÉTODO CPR}

Melhoramento ou reforço de solos moles á a modificação de suas características, de modo a atender os resultados esperados. A tecnologia CPR de tratamento de solos moles baseia-se na teoria da consolidação do solo, ou seja, induzindo-o a perder água e 
volume de modo a modificar sua resistência e, consequentemente, adicionando rigidez. A estratégia de compressão do solo baseia-se

na teoria de expansão de cavidades, que possibilita atuar ao longo de toda a profundidade do depósito de solo mole.
O modelo de tratamento CPR pode ser explicado pela célula unitária composta por quatro bulbos de compressão e adensamento, realizados via expansão de cavidades, que acabam por isolar um bulbo de solo em seu centro, comprimindo-o, confinando-o e consolidando-o, conforme a figura 15.

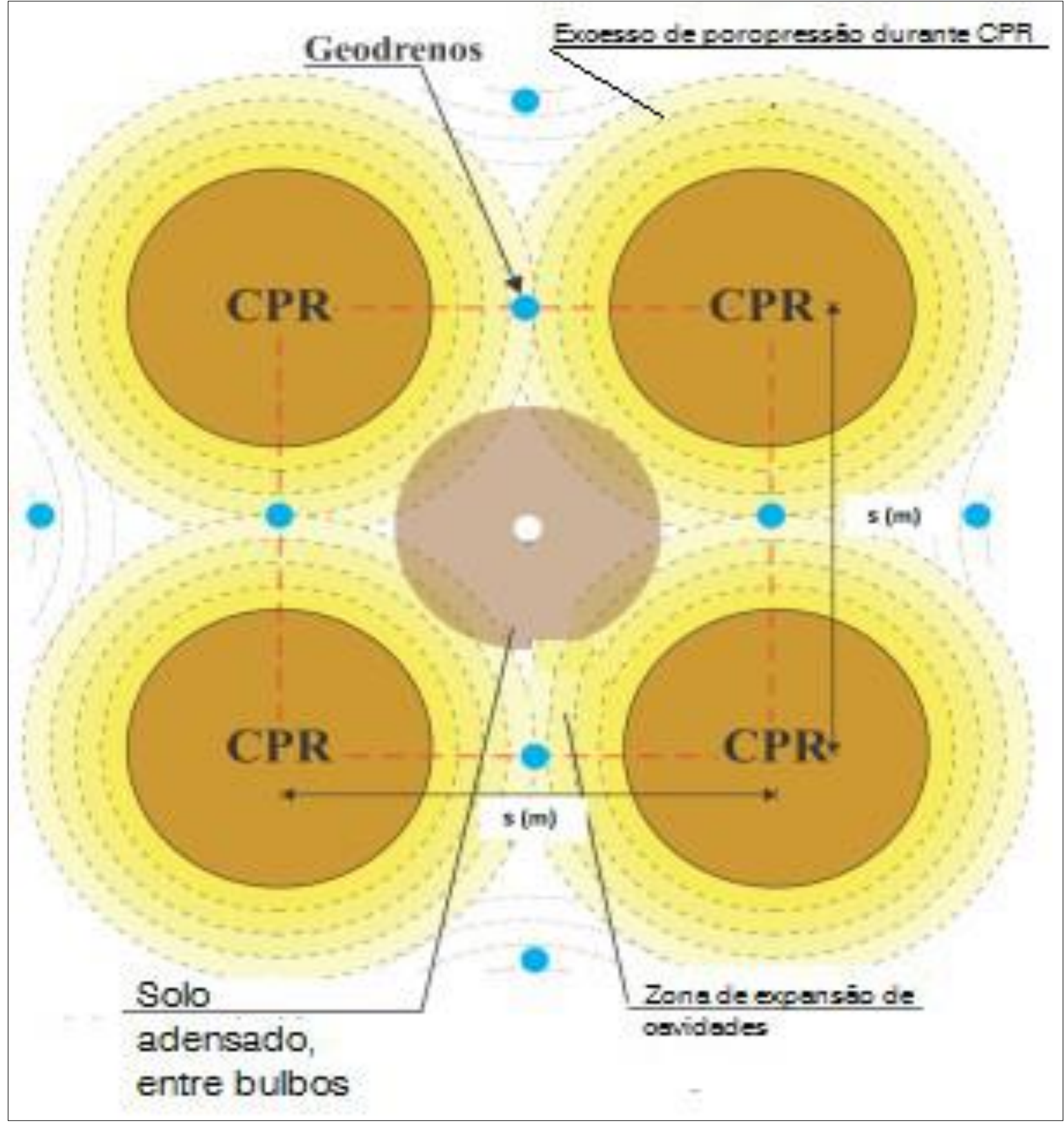

Figura 15. Célula Unitária.

Fonte: Autores, (2015).

Com isso, a análise através de testes com ensaios pressiométricos possibilitará a observar todo o contexto da célula unitária, ou seja, do solo compósito. Por isso, a necessidade de aferir todo o serviço do CPR, que basicamente utiliza sonda cilíndrica inflável, posicionada a diversas profundidades. O pressiômetro utiliza unidade de controle hidráulico para carregar a sonda, monitorando a resposta do solo na profundidade ensaiada. 


\section{IV.5 ANÁLISE DE FORMAÇÃO DAS COLUNAS}

A análise feita nas sondagens realizadas antes do tratamento do solo demonstra qual o tipo de solo do local de aplicação do método. Após o tratamento do solo, demonstra resultados de um super adensamento do sole mole dando maior resistência quanto à tensão admissível. O método traz vantagens quando a comparados com outros métodos porque conduz velocidade da onda cisalhante ao máximo junto ao furo, diminuindo à medida que se afasta dele. Efetivamente, diminui-se a quantidade de poros fazendo-se com que o esqueleto sólido entre em carga, obtendo-se um novo estado de equilíbrio, agora estável.
O que é relativamente adequável a construção de Portos, onde pela região apresenta solos extremamente moles.

\section{IV.6 COMPROVAÇÃO DO MÉTODO APLICADO}

Como demonstrados com os ensaios feitos antes da execução do CPR, conforme a figura 1 . Os valores de Nspt de acordo a norma brasileira [5] apresenta uma classificação para os estados de compacidade relativa, no caso de solos grossos e de consistência para solos finos, em função do índice de resistência a penetração, conforme apresentado na figura 16.

\begin{tabular}{|c|c|c|}
\hline Solo & N\&T & $\begin{array}{l}\text { Classificaça (Compacidade da } \\
\text { areia ou Consistência da argila) }\end{array}$ \\
\hline \multirow{5}{*}{ Areila e silte arenoso } & $<4$ & Fofa $(0)$ \\
\hline & $5 a 8$ & Pouco compacta (o) \\
\hline & 9 a 18 & Medianamente compacta (o) \\
\hline & 19 a 40 & Compacta $(0)$ \\
\hline & $>40$ & Muito compacta (o) \\
\hline \multirow{5}{*}{ Argila e silte argiloso } & $<2$ & Muito mole \\
\hline & 365 & Mole \\
\hline & 6 a 10 & Média $(0)$ \\
\hline & 11 a 19 & Rija $(0)$ \\
\hline & $>19$ & Dura $(0)$ \\
\hline
\end{tabular}

Figura 16. Classificação dos solos.

Fonte:[5].

Neste caso a resistência a Nspt variaram de 3 a 10 que são solos conforme a tabela 1 classificados: fofos, pouco compactados e moles ou muito moles. Contudo, as análises acompanhadas em diversos pontos antes da execução do método CPR, podem ser mostradas no gráfico da figura 17 como uma relação das quantidades de golpes pela profundidade do solo de metro em metro: 


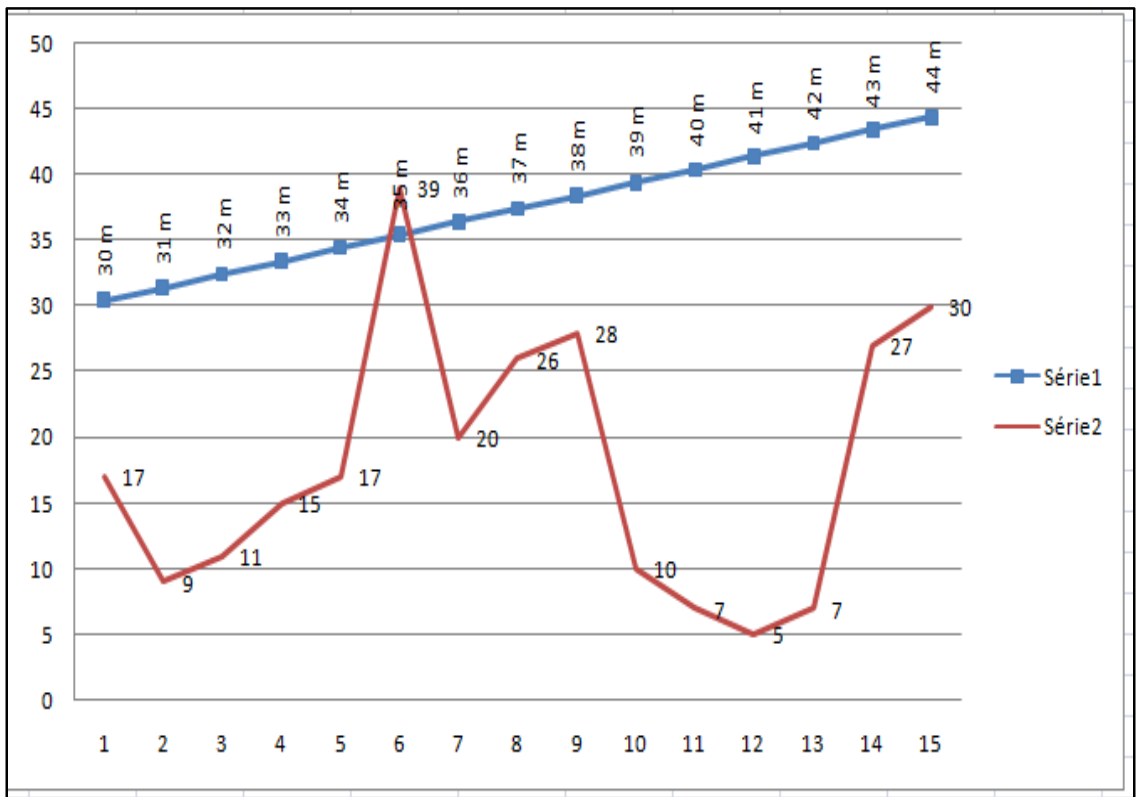

Figura 17. Gráfico da Sondagem SPT.

Fonte: Autores, (2015).

Diante as sondagens analisadas antes a execução do tratamento do solo podemos afirmar que: Os pontos de pico (mostrado na linha vermelha), que apresentam maiores golpes por determinada profundidade, são os locais de solo mais rígidos, já nos pontos de menores picos, são solos extremamente moles que não servem para aplicações de cargas, pois são considerados fracos para tensões admissíveis aplicadas.

Com isso, para a comprovação e acompanhamento do tratamento nos solos considerados moles, foi utilizado o método com piozômetro, faziam o levantamento da por opressão original ao longo dos trechos antes do CPR. Excesso e dissipação máximos da poropressão são controladas, durante o CPR, com piozômetros de corda vibrantes atestando o grau de adensamento alcançado.
O ensaio pressiométrico consiste na aplicação de pressões uniformes às paredes de um furo de sondagem, através de uma membrana flexível montada em uma sonda, no interior do solo ou rocha branda. O objetivo é determinar o comportamento tensãodeformação do material in situ.

De acordo com SOARES (1997), além de possibilitar a obtenção de uma relação tensão x deformação (deformação planar), o ensaio pressiométrico permite obter uma pressão de escoamento e uma pressão limite (ruptura).

Os ensaios foram executados mediante deformação controlada, onde incrementos de volume de água eram liberados da caixa de controle para a sonda, e vice-versa, e as pressões correspondentes eram assinaladas e foram avaliados conforme a figura 18 .

\begin{tabular}{|c|c|c|}
\hline Tipo de Solo & $\begin{array}{c}\text { Pressão } \\
\text { limite líquida } \\
\mathrm{P}_{\mathrm{L}}^{*}(\mathrm{kPa})\end{array}$ & $\begin{array}{l}\text { Módulo } \\
\text { Presiométrico } \\
\mathrm{E}_{\mathrm{m}}(\mathrm{kPa})\end{array}$ \\
\hline Argila mole & $0-200$ & $0-2.500$ \\
\hline Argila média & $200-400$ & $2.500-5.000$ \\
\hline Argila rija & $400-800$ & $5.000-12.000$ \\
\hline $\begin{array}{l}\text { Argila muito } \\
\text { rija }\end{array}$ & $800-1.600$ & $12.000-25.000$ \\
\hline Argila dura & $>1.600$ & $>25.000$ \\
\hline $\begin{array}{l}\text { Areia fofa } \\
\text { Areia }\end{array}$ & $0-500$ & $0-3.500$ \\
\hline $\begin{array}{l}\text { medianamente } \\
\text { compacta }\end{array}$ & $500-1.500$ & $3.500-12.000$ \\
\hline $\begin{array}{l}\text { Areia } \\
\text { compacta }\end{array}$ & $1.500-2.500$ & $12.000-22.500$ \\
\hline $\begin{array}{l}\text { Areiam muito } \\
\text { compacta }\end{array}$ & $>2.500$ & $>22.500$ \\
\hline
\end{tabular}

Figura 18. Valores pressiométricos.

Fonte: Autores, (2015). 


\section{CONCLUSÃO}

Neste trabalho foi apresentado uma metodologia de dimensionamento estrutural para determinação de área de seção transversal de armaduras longitudinais de tração de (As) positivas e (A's) negativas de lajes maciças do pavimento cobertura de edificação residencial pelo método teórico de Bares-Czerny bem como utilizando a ferramenta computacional Eberick v9, a fim de realizar o comparativo dos resultados de (As e A's) obtidos. Concluímos que ambos os métodos atendem às finalidades propostas.

Entretanto, observamos que a principal vantagem obtida em utilizar a teoria de Barez-Czerny para a mensuração de (As e A's) é de que os engenheiros projetistas aplicam em todo o método os conceitos fundamentais de análise estrutural, tais como: condições de equilíbrio, tipos de vínculos, estaticidade e estabilidade, dentre outros, bem como recomendações normativas. Entretanto apresenta a desvantagem de tornar a edificação muito robusta, aplicando maiores cargas às fundações e, consequentemente, elevando os custos de construção, além de ser menos eficaz em termos de tempo de produção do projeto estrutural.

Por outro lado a utilização da ferramenta computacional Eberick v9 para o dimensionamento proposto torna possível projetar estruturas mais esbeltas, aplicando menores cargas as fundações, produzindo excelentes projetos em prazos muito menores e fazendo com que os custos de horas de projetos sejam drasticamente reduzidos. Adicionalmente possibilita uma melhor análise da estrutura projetada. Apresenta no entanto a desvantagem que qualquer ferramenta eletrônica possui, qual seja, de não ser inteligente (autônomo), necessitando da expertise do projetista, devendo o mesmo não confiar simplesmente nos resultados da ferramenta e nunca desprezar seus conhecimentos próprios. Como etapa posterior a este trabalho, pretendemos estudar o comportamento de todos os elementos estruturais de edificação de CA a fim de enriquecermos os temas aqui abordados, servindo de base de informação/consulta a todos os interessados nos tópicos ora abordados. As a further step to this work, we intend to study the behavior of structural elements AC building in order to enrich the topics covered, providing the basis of information / consultation to all interested in the topics addressed herein.

\section{AGRADECIMENTOS}

Ao Centro Universitário do Norte (UNINORTE) pelo apoio a pesquisa.

\section{REFERÊNCIAS}

[1] ABNT - Associação de normas técnicas. NBR 5892: Norma para datar. Rio de Janeiro, 1989.

[2] Instituto Nacional de propriedade Industrial (INPI). 2016.

[3] www.googleEarth.com. Acesso em <12 setembro de 2016>

[4] Instituto Militar de Engenharia. Área de concentração e linhas de pesquisas. Disponível em: http://transportes.ime.eb.br/. Acesso em: 05/Outubro/2016.

[5] NBR 7250-92. Identificação e descrição de amostras de solo obtidas em sondagens de simples reconhecimentos dos solos.

[6] ABNT - Associação de normas técnicas. NBR 5892: Norma para datar. Rio de Janeiro, 1989.

[7] NBR 6484/2001. Solo- Sondagens de simples reconhecimento com SPT-Método de Ensaio, Rio de Janeiro, 2001.

[8] Engegraut Geotecnia e Engenharia LTDA, Rio de Janeiro. 